\section{Removable orthodontic appliance for extrusion of single upper anterior tooth and crowding lower anterior in adult: a case report}

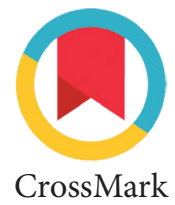

\author{
Zenia Adindaputri, ${ }^{*}$ Sri Suparwitri
}

\title{
Abstract
}

Objective: Supra-eruption maxillary incisor is a usual case that finding in dental practice. Over eruption of such tooth and crowding can lead for traumatic occlusion and functional disturbance. This case report presented patient 26-year-old female class I malocclusion with supra-eruption right central incisor maxillary caused of traumatic and anterior mandibular mild crowding.

Methods: This treatment option indicated for orthodontic removable appliance due to small discrepancy. Interproximal enamel reduction as an alternative to solve the problem of mandibular negative space discrepancy. The simple modification in removable orthodontic appliance used with glass ionomer cement on labial surface of right central incisor maxillary. Malposition of lower teeth was corrected with modification of the Hawley appliance consisting of labial arch, adam clasp, and simple spring.

Results: After 5 months 14 days treatment, supra-eruption right central incisor maxillary has corrected usage of removable orthodontic appliance with glass ionomer cement on labial surface. Anterior mandibular mild crowding has corrected with removable appliance.

Conclusion: Successful orthodontic results with this treatment option will achieve by a careful diagnosis, establish with the aid of a diagnostic setup, professional skills, and patient cooperative.
Department of Orthodontic, Faculty of Dentistry, Gadjah Mada University, Yogyakarta, Indonesia
Keyword: Mild crowding anterior, Removable orthodontic appliance, Single tooth intrusion

Cite this Article: Adindaputri Z, Suparwitri S. 2020. Removable orthodontic appliance for extrusion of single upper anterior tooth and crowding lower anterior in adult: Case report. Journal of Dentomaxillofacial Science 5(1): 66-68. D0I: 10.15562/jdmfs.v5i1.977

\section{Introduction}

Supra-eruption maxillary incisor is a usual case that finding in dental practice. Over eruption of such tooth and crowding can lead for traumatic occlusion and functional disturbance. ${ }^{1,2}$

Discrepancy of the incisal edge of the anterior teeth, especially in the upper jaw, could affect of dental aesthetics. The vertical position of incisors teeth have a important role in terms of esthetics. ${ }^{3}$ A diagnostic skills and application of criteria from the clinician are needed to improve the success of orthodontic treatment. ${ }^{4}$ In this article will describe case report about using orthodontic removable to resolve the main problem from patient is supra-eruption upper right central incisors and mild crowding lower anterior.

"Correspondence to:

Zenia Adindaputri, Department of Orthodontic, Faculty of Dentistry, Universitas Gadjah Mada, Yogyakarta, Indonesia zeniadinda@gmail.com

Received: 30 August 2019 Revised: 9 March 2020 Accepted: 29 March 2020 Available Online: 1 April 2020

\section{Case Report}

The patient, a 26-year-old female, report to our department, Prof. Soedomo Dental Hospital Faculty of Dentistry Gadjah Mada University, Department of orthodontics. She was complaining of an incisal edge discrepancy between her upper central incisors and she also complaining crowding at lower teeth. She wants aligning her teeth because interfere her smile. She wants the effective cost treatment. On intraoral examination it was found that the incisal edge of her upper right central incisor was positioned $1.6 \mathrm{~mm}$ lower than that of upper left incisor figure 1. On lower anterior teeth was found that negative discrepancy is $1.5 \mathrm{~mm}$ figure 2 . The overjet was $3 \mathrm{~mm}$ and the overbite was $2.7 \mathrm{~mm}$. No periodontal and other problems were found during radiographic assessment of the upper incisors. A short course of fixed orthodontic treatment was proposed for her, but she rejected it because she wants the effective cost treatment. Intrusion of the tooth and correction the crowding of anterior lower teeth was the aim without correcting the crown angulation.

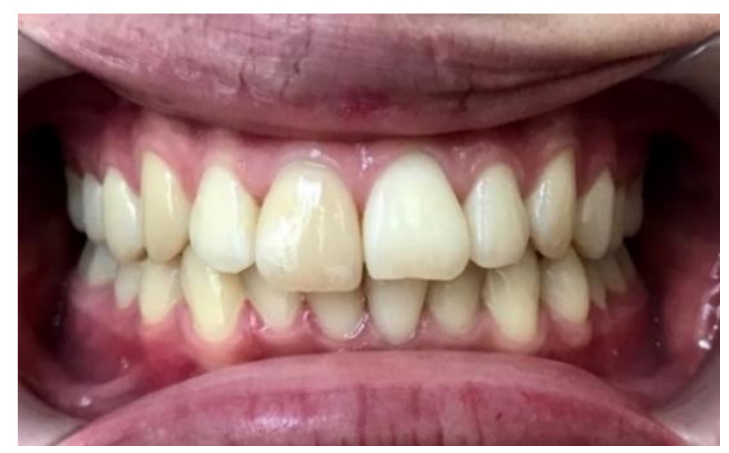

Figure 1 Intraoral view before treatment (anterior) 


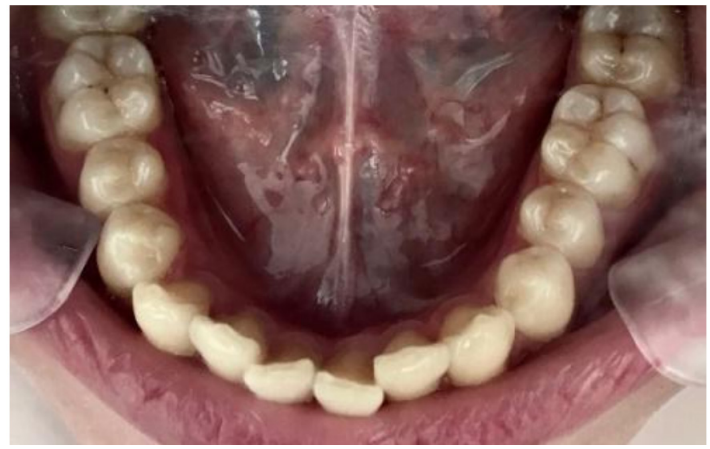

Figure 2 Lower teeth before treatment (occlusal-view)

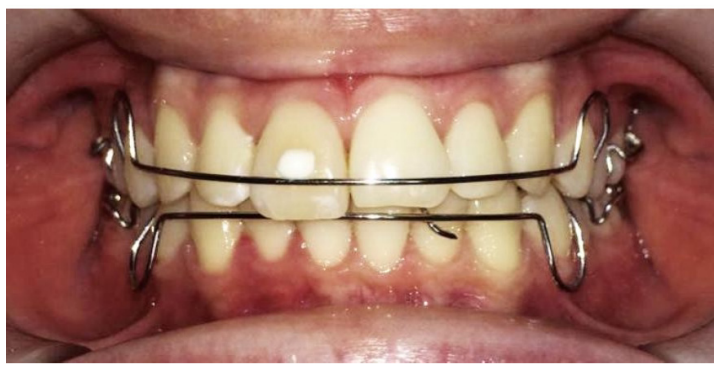

Figure 3 Removable appliance orthodontic with glass ionomer cement on labial surface tooth 11

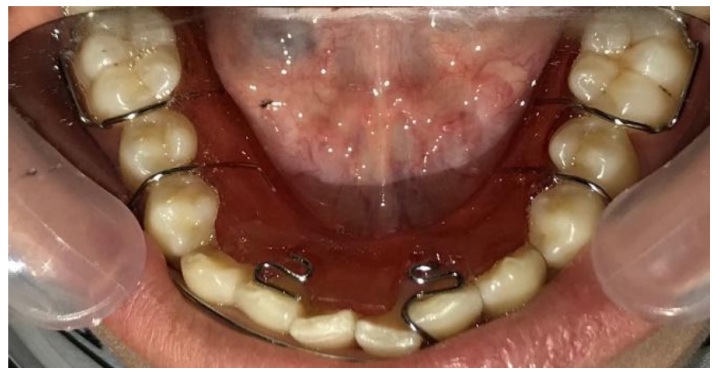

Figure 4 Removable Orthodontic Appliance with simple spring

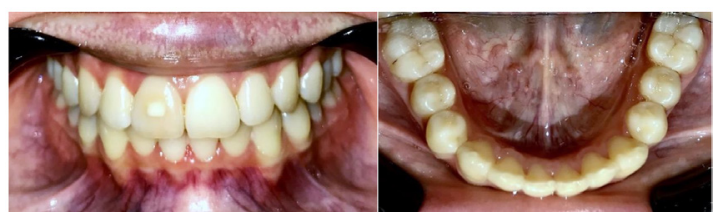

Figure 5 After treatment

The appliance was a simple modification of the Hawley appliance. Hawley appliance which is removable appliance consisting of labial arch and adam clasp as its wire components and an acrylic plate is a simple removable appliance for correcting minor malocclusion figure 3. We have application of glass ionomer cement on labial surface of upper right central incisors. That aims to intrusion the upper right central incisors with places the labial arch inferior of glass ionomer cement figure 4 .
Malposition of lower teeth was corrected with modification of the Hawley appliance consisting of labial arch, adam clasp, and simple spring. Inter proximal reduction as an alternative to solve the problem of negative space discrepancy of lower teeth. The reduction was done on $31,32,41,42$ by $0.4 \mathrm{~mm}$ each tooth.

Patient was instructed to use removable orthodontic appliance every day and to clean after meal. The appliance should be used every night. Patient was advised to check the progress once every 7-10 days figure 5 .

\section{Discussion}

Incisal edge position of maxillary incisor is the most important determinant in smile creation because on set, it serves a reference point to decide the proper tooth proportion and gingival levels. The parameters used to help establish the maxillary incisal edge position are degree of tooth display, phonetics, and patient input. ${ }^{4,5}$ Tooth intrusion should only be attempted when the periodontal condition is under control and no pockets of more than $3 \mathrm{~mm} .{ }^{6}$ If intrusion movement of a group of teeth were needed, a fixed orthodontic treatment might be necessary. For the uncomplicated cases, the intrusion of one anterior tooth could be done with a removable orthodontic appliance. ${ }^{7}$ This patient presented with vertical discrepancy of $1,6 \mathrm{~mm}$ in the level of incisal edge. Both laypersons and orthodontists can detect a discrepancy from $1,5 \mathrm{~mm}$ to $2 \mathrm{~mm}$, whereas orthodontists are critical and can detect even $0,5 \mathrm{~mm}$ discrepancy. ${ }^{8}$ The limitation that can ace ptable for gingival margin discrepancy between the two incisors is $2,1 \mathrm{~mm} .{ }^{9,10}$

Despite the use of fix orthodontic appliance is the ideal treatment option for this case, but the treatment planning must with patient agreement. The explanation using of fix orthodontic was disagreement by patient because of the cost. So, orthodontic removable appliance is an alternative treatment planning for this case. Orthodontic removable appliance at this case giving the light intrusion force without buccal tipping or palatal tipping at the upper right incisor centralis. Very important to apply light force during intrusion force. The glass ionomer cement put on the labial surface at the labial arch placed. The diameter of glass ionomer cement is $2 \mathrm{~mm}$.

The purpose of interproximal enamel reduction (IER) is to get the alignment from the teeth or to keep the alignment for long time. ${ }^{11,12}$ Interproximal enamel reduction may offer an attractive alternative to extraction therapy because it allows transverse arch dimension and anterior inclinations to be 
maintained. ${ }^{13}$ Mild crowding with discrepancy less than $5 \mathrm{~mm}$, interproximal enamel reduction is a good alternative. ${ }^{14}$ The amount of enamel that must be removed from each side of the tooth by stripping is only $0.25-0.50 \mathrm{~mm}$ in total, and the dentin will not be exposed. The total maximum amount of stripping recommended is $4 \mathrm{~mm}$ in the upper anterior teeth and $3 \mathrm{~mm}$ for the mandibular incisor. ${ }^{15}$ After the IER, the enamel must be polished using finishing strips. ${ }^{16,17}$

The treatment in this article with interproximal reduction the lower incisor, each side of the teeth stripping $0.4 \mathrm{~mm}$. The Bolton analysis is the size of mandibular teeth more than normal and the patient have a low risk for caries and good oral hygiene, therefore interproximal enamel reduction is approval. ${ }^{17,18}$ The activation of upper labial arch by add the bending to gingival at the mesial $\mathrm{U}$ loop for intrusion the upper central incisor. The activation simple spring and labial arch of lower teeth was done to correction the lower incisor teeth. The supra-erupted upper right central incisor has corrected by orthodontic removable appliance with glass ionomer cement modification after 2 months treatment, and the mild crowding of mandibular has corrected after 5 months 14 days.

After the treatment has done, patient was instructed by using clear retainer for 6 months. The clear retainer purposes of retention, maintenance of aligning and intrusion of right upper central incisor simultaneously. ${ }^{19,20}$

\section{Conclusion}

The simple modification in removable orthodontic appliance can using to correction the supra-eruption incisor and mild crowding at adult patient. Successful orthodontic results with this treatment option will achieve by a careful diagnosis, establish with the aid of a diagnostic setup, professional skills, and patient cooperative.

\section{Acknowledgment}

The authors would like to thanks to patient who have approved her case for publication, Prof. Soedomo Dental Hospital Faculty of Dentistry Gadjah Mada University where the patient has been treated until finished, and Orthodontic Department of Gadjah Mada University.

\section{Conflict of Interest}

The authors report no conflict of interest.

\section{References}

1. Heravi F, Bayani S, Madani AS, et al. Intrusion of supraerupted molars using miniscrew: Clinical success and root resorption. Am J Orthod Dentofacial Orthop 2011;139: 170-175.

2. Baheti MJ, Gharat NV, Toshniwal NG. Simple and cost-effective approach for maxillary bilateral posterior intusion: nandlal toshniwal rural dental college double intrusion arch. Apos Trends in Orthodontics 2015;5: 225-228.

3. Zachrisson BU. Esthetic factors involved in anterior tooth display and the smile: vertical dimension. J Clin Orthod 1998;32: 432-445.

4. Irwansyah, M, Erwansyah, E. Penilaian tingkat keberhasilan perawatan ortodontik dengan piranti lepasan berdasarkan indeks PAR. J Dentomaxillofac Sci 2011;10: 144-150.

5. Bloom DR. Increasing occlusal vertical dimension-why, when, how. Br Dent J 2006;200: 251-256.

6. Melsen, B, Agerbaek N, Markenstam G. Intrusion of incisor in adult patients with marginal bone loss. Am J Orthod Dentofac Orthop 1989;96: 232-241.

7. Arici S. An easy way of intruding an upper central incisor. British Dent J 2004;197: 543-544.

8. Kokich VO, Kokich VG, Kiyak HA. Perceptions of dental professionals and laypersons to altered dental esthetics: asymmetric and symmetric situation. Am J Orthod Dentofacial Orthop 2006;130: 141-151.

9. Springer NC, Chang C, Fields HW, et al. Smile aesthetics from layperson's perspective. Am J Orthod Dentofacial Orthop 2011;139: 91-101.

10. Ker AJ, Chan R, Fields HW, et al. Aesthetics and smile characteristics from the layperson's perspective: a computer-based survey study. J Am Dent Assoc 2008;139: 1318-1327.

11. Betteridge MA. The effects of interdental stripping on the labial segments evaluated one year out of retention. Br J Orthod 1981;8: 1993-1997.

12. Livas C, Jongsma AC, Ren Y. Enamel reduction techniques in orthodontics: a literature review. Open Dentist J 2013;7: 146-151.

13. Stroud JL, English J, Buschang PH. Enamel thickness of the posterior dentition: its implication for nonextraction treatment. Angle Orthod 1998;68: 141-146.

14. Zachrison BU, Minster L, Ogaard B, et al. Dental health assessed after interproximal enamel reduction: caries risk in posterior teeth. J Orthod Dentofacial Orthop 2011;139: 90-98.

15. Harfin J, Urena AJ. Achieving clinical success in lingual orthodontic. New York: Springer; 2015. p. 47-58.

16. Rao V, George AM, Sahu SK, et al. Surface roughness evaluation of enamel after various stripping methods by using profilometer. Arch Oral Sci Res 2011;1: 190-197.

17. Frindel C. Clear thinking about interproximal stripping, J Dentofacial Anom Orthod 2010;13: 187-199.

18. Jadhav S, Vattipelli S, Pavitra, M. Interproximal enamel reduction in comprehensive orthodontic treatment: a review. Indian J Stomatol 2011;2: 245-248.

19. Gopal R, Tripath T, Rai P, et al. Esthetic Simultaneous Intrusion and Retention (E-SIR) Appliance. J Clin Diagnostic Res 2018;12: 16-17.

20. Demir A, Babacan H, Nalcaci R, et al. Comparison of retention characteristics of essix and hawley retainers. Korean J Orthod 2012;42: 255-262.

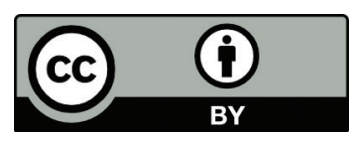

This work is licensed under a Creative Commons Attribution 